\title{
РОЛЬ ЧАСТНОГО И ПУБЛИЧНОГО ПРАВА В СТРОЕНИИ ПРАВА
}

\section{THE ROLE OF PRIVATE AND PUBLIC LAW IN THE STRUCTURE OF LAW}

\begin{abstract}
The Authors of the article argue that private and public law, along with the principles of law, are elements of the structure of law and are present in every legal system. The Authors propose an integrated approach to the distinction between private and public law and pay attention to the nature and significance of such a distinction.

The article discusses the interrelation of the dualistic division of law and the division of law into branches, into separate norms. The paper emphasizes that the division of law into private and public is universal and does not directly depend on any type (kind) of law. At the same time, the quality of separate norms and institutions of law, private and public law in general, should be assessed according to their compliance with the general principles of law.

Besides, the article elucidates and assesses the main approaches to the dichotomy of law, to understand private and public law, to highlight the criteria for their differentiation. Special attention is paid to the critical assessment of the method of legal regulation, the composition of participants in legal relations, and legal culture.
\end{abstract}

Keywords: private law, public law, dualism of law, structure of law, rule of law

Ключевые слова: частное право, публичное права, дуализм права, строение права, норма права

\section{Введение}

Вопрос о делении права на публичное и частное является традиционным для правоведения. Этот вопрос важен с позиций решения многих других вопросов юридической науки, имеет большое практическое значение. Он также влияет на решение проблем сущности и содержания права, правопонимания, идеологии правового регулирования, иерархии юридических источников, координации норм права, институтов и отраслей законодательства.

Рассмотреть все эти вопросы в рамках настоящей статьи не представляется возможным. Мы предлагаем уделить внимание рассмотрению дуалистической теории (основного разделения права) с позиций структуры права, с позиций деления позитивного права на нормы, институты и отрасли. 


\section{Основная часть}

Прежде всего надо сказать, что концепция частного - публичного права уже много столетий является для юриспруденции традиционной, даже несмотря на существенные различия в ее трактовках.

Известно, что разделение права на частное и публичное встречается уже у древнеримского юриста Ульпиана, понимавшего под частным правом положения, относящиеся к интересам (пользе) отдельных лиц (индивидов), а под публичным - положения, относящиеся к интересам и потребностям государства. Таким образом, изначально критерием разграничения частного и публичного права называли именно превалирующий интерес субъектов права. Несмотря на относительную определенность и сопоставительный характер, данный критерий востребован вплоть до настоящего времени. Однако, оперируя к нему, не стоит забывать, что «... уголовное право обязано своим развитием тому, что регламентировало по большей части отношения между частными лицами... и... не лежало полностью в сфере «публичного права»» [Давид, Жоффре-Спинози 2007, с. 49].

Г. Дж. Берман указал, что западная традиция регламентации публичных отношений обусловлена отделением государства от церкви [Берман 1988, с. 278]. Согласно Дж.Н. Мерриману идеи о правовом значении индивидуальной автономии являются в германской правовой доктрине основополагающими и подпадают именно под частноправовое направление [Merriman 1985, c. 91, 98].

Российский правовед Г.В. Мальцев характеризует частное право, представленное гражданско-правовым регулированием, такими признаками как независимость и свобода воли субъектов права, свобода соглашений, равенство сторон, децентрализация правовых связей. Он же указывает, что административно-правовое регулирование противоположно регулированию гражданско-правовому [Мальцев 2004, с. 718-736]. По мнению В.В. Болговой, «Римское право, дав традицию терминологического обозначения частного и публичного права, не предполагало именно разграничения права на две самостоятельные области... Все исследования показывают, что процесс теоретического оформления идеи дихотомии права относится к Новому времени... Для сфер частного и публичного права создаются самостоятельные юрисдикционные системы» [Болгова 2009, с. 111-113].
Многие отмечают, что уже в римском праве частное и публичное право являлись содержательными и стабильно существующими элементами права [Girard, von Mayr 1908, с. 7]. Кроме того, существует позиция, согласно которой частное и публичное право являются правовыми началами (принципами), отражающими сам дух права. Согласно этой позиции, все нормы позитивного права должны соответствовать тем принципам, которые характерны или для частного, или, соответственно, для публичного права [Князев]. По нашему убеждению, основное разделение права не носит дихотомического характера, не является взаимоисключающим. Дуализм права предполагает не обособление двух противоположных сфер, а выявление и различение основных, фундаментальных направлений правового воздействия, разделение которых не означает четкого обособления или какого-либо противопоставления.

В трактовках частного и публичного права в юридической литературе встречаются весьма специфические и неоднозначные мнения.

Так, Н.В. Разуваев указывает на наличие в духовной культуре общества двух самостоятельных и специфических сфер: правовой и политической. В правовом аспекте этим сферам соответствуют частное и публичное право. «Так, уже в Древней Индии правоведы выделяли две основные юридические категории: дхарма и артха. Соответственно, существовали два жанра юридической литературы, составлявшие в своей совокупности систему древнеиндийского позитивного права: дхармашастры и артхашастры. Первые представляли собой предписания морально-этического и собственно юридического характера, посвященные регулированию семейных, имущественных, обязательственных и прочих отношений, образующих предмет частного права. Вторые содержали предписания, касающиеся вопросов политики, войны и мира, государственного управления и т.п., т.е. всего того, что входит в сферу публично-правового регулирования» [Разуваев 2002, с. 41-43].

На основании изложенного Н.В. Разуваев заключает, что разница между частным и публичным правом обуславливается их принадлежностью к неодинаковым сферам духовной культуры, каждая из которых формирует присущий именно ей юридический «... образ человека в зависимости от того, какие его особенности являются релевантными именно для данной сферы» [Разуваев 2002, с. 41-43]. 
Вместе с тем, Н.В. Разуваев тут же отмечает: «При этом необходимо отметить, что подобные расхождения далеко не всегда сопутствуют разграничению частного и публичного права. Так, в Древней Греции (например, в Афинах) сын находился под властью отца семейства лишь до наступления совершеннолетия, после чего получал всю полноту как политических, так и имущественных прав. Видимо, указанное обстоятельство в числе прочих не позволило древнегреческим философам и правоведам (даже таким значительным, как Аристотель) осознать различие между частным и публичным правом и провести соответствующие разграничения» [Разуваев 2002, с. 41-43].

Не соглашаясь с автором, заметим, что получение индивидом политических и (или) имущественных прав само по себе не может свидетельствовать ни о наличии, ни об отсутствии частного и (или) публичного права. То, что в некоторых обществах мировоззренческая и доктринальная мысль (как это было, например, в советской юриспруденции на протяжении более чем половины XX в.) не ориентировалась на дуалистическую модель, также не может выступать основанием признания или отрицания частного и публичного права как структурных элементов права.

Кроме того, нам представляется, что правовая культура является существенным показателем правовой системы социума. Она отображает правовой менталитет, демонстрирует конкретно-исторической тип правовой общности. Вместе с тем, неверно и нецелесообразно считать правовую культуру основным критерием деления права на частное и публичное. По указанным причинам при анализе воззрений Н.В. Разуваева нам вспоминается следующее высказывание: «Забвение самих правовых норм, самого права при построении системы права - вот наиболее слабая черта рассматриваемой позиции» [Разуваев 2002, с. 41-43]. Сознание, идеология, традиции, культура характеризуют внешние признаки правовой системы в целом, но не могут выступать критериями выявления закономерных, стабильных и строеобразующих элементов права, относящихся к внутреннему строению права.

Существует также позиция, авторы которой выводят вопрос о дихотомии права из сферы объективного права. Эта позиция берет свое начало от Р. фон Иеринга. В российской юридической доктрине приверженность ей выражал В.П. Мозолин, который указывал: «Объективное право всегда имеет публичный характер. Правовые же отношения, возникающие на основании норм объективного права, могут быть публично-правовыми и частноправовыми. Соответственно, аналогичная градация применима к субъективным правам участников правоотношения в обществе с рыночной экономикой» [Мозолин 2003, с. 113]. Нормативные правовые акты действительно всегда исходят от государства и поэтому всегда отражают его волю, закрепляют значимые, с позиций общественного управления, интересы, потребности, установки, цели. В этом смысле, «в реальной действительности действующая правовая норма всегда... создает соответствующее ей правоотношение» [Пионтковский 1958, c. 28], модель которого задается именно публичной властью. Верно, и то, что субъективные правомочия реализуются в разных направлениях и могут носить как личный, так и общественный характер.

Однако сказанное не опровергает того, что содержание права (в наиболее общем смысле) очень объемно, многогранно. В нем существуют и частный, и публичный элементы (а также исходное, скрепляющее, объединяющее их начало). Это предопределено адресностью правового воздействия. Субъектами права являются далеко не только публично-правовые образования, но и индивиды, лица в собственном смысле слова. Причем именно последние являются первичными субъектами права. Поэтому крайне сложно, если вообще возможно, представить себе правовую систему, которая совсем не содержит норм, относящихся именно к области частного права.

Е.А. Суханов, обращаясь к тематике дуалистического строения права, указывает: «В наших условиях гражданское и частное право всегда совпадали и совпадают... Дореволюционному русскому праву... не был присущ известный дуализм частного права, т.е. его деление на гражданское и торговое право... Данное обстоятельство следует иметь в виду при ссылках на зарубежный опыт... Этот опыт весьма разнороден и обусловлен во многом историческими и другими традициями... Достаточно упомянуть о системе «общего права», вообще исключающей его формальное деление на публичное и частное (хотя, фактически, и там проводиться такое различие). Состав... самого частного права различается и в континентальных правовых системах. Например, Италия, Швейцария и Нидерланды объединили (унифицировали) гражданское и торговое право, устранив их традиционный дуализм. Трудовое и гражданско-процессуальное право в одних странах относят к сфере частного 
права, а в других - публичного и т.д.» [Суханов 1994, c. 26, 27]. Далее Е.А. Суханов формулирует весьма ценный вывод о том, что в мире не существует каких-либо установленных, правильных и должных схем (моделей) формирования правовых систем.

Е.А. Суханов совершенно верно подчеркивает, что идея о непризнании частного права, свойственная советской правовой науке, равно как и ее относительно малая распространенность в англо-саксонской правовой семье, не означает действительной ликвидации или отсутствия частного права. Деление частного права также не означает того, что оно прекратило свое существование. Это означает лишь то, что для самого частного (публичного) права в конкретной правовой системе применяется та или иная внутренняя классификация.

Авторы настоящей работы также не могут не согласиться с тем, что, независимо от того, признает ли доктрина и законодатель частное право, его действие можно пронаблюдать в любой правовой системе. Сфера частноправового регулирования может быть более или менее широкой, но само ее наличие присуще строению права всегда. Доктринальное, или прямое государственное признание (или его отсутствие), в данном вопросе также не имеет решающего характера, так как дает характеристику явления или демонстрирует отношение к нему, но не влияет на его внутреннее строение.

Споры о соотношении гражданского и торгового права, а также гражданского и частного права уже можно назвать классическими для российской и зарубежной теории частного права. В составе частного права выделяют очень разные компоненты. Например, гражданское, семейное, торговое и международное частное право; гражданское, наследственное, авторское, изобретательское, трудовое и предпринимательское право; гражданское, трудовое и семейное право. В целом же, по обозначенному вопросу действительно выделяют две базовые позиции: монистическую и дуалистическую.

Согласно монистической модели частное право отождествляется с гражданским правом. При этом торговое право не выделяется в качестве самостоятельной отрасли права и рассматривается именно как часть гражданского права. По верному замечанию В.В. Ровного, «общепринятое рациональное деление системы права по предметно-отраслевому признаку, наряду с полным или частичным отождествлением частного права с гражданским, допустимы условно» [Ровный 2000, с. 2, 5, 6].

Согласно второй позиции (исторически связывающейся со сбором морских торговых обычаев) в системе частного права гражданское право занимает центральное место. Вместе с тем, частное право шире права гражданского, не исчерпывается им и включает в себя еще ряд отраслей.

Вопрос о соотношении гражданского и торгового права при этом решается одним из двух способов. При первом способе гражданское и торговое право рассматриваются как самостоятельные, обособленные (хотя, безусловно, и взаимосвязанные) элементы частного права. При втором способе нормы торгового права входят в содержание каких-либо иных отраслей права, выделяемых в составе частного права. Таким образом, дуалистическая модель частного права характеризуется наличием «жесткого» и «мягкого» направлений. Основное различие между ними состоит в том, что при первом применение норм гражданского права к торговым правоотношениям допускается только в порядке аналогии, в то время как при втором очень значительное количество норм торгового права входит в предмет гражданско-правового регулирования.

В любом случае, для дуалистической модели частного права характерно одновременное действие как гражданского, так и торгового кодексов, что типично для многих государств романо-германской правовой семьи.

Также очень часто ученые проявляют интерес к вопросу о соотношении гражданского права с хозяйственным. Изначальную проработку теория хозяйственного права получила в германской правой доктрине. При этом в юридической науке до сих пор нет однозначного и (или) общепризнанного ответа на вопрос о сущности, о природе хозяйственного права. Чаще всего хозяйственное право трактуют как частно-публичное. В рамках данной трактовки выделяются две основные позиции. Согласно первой хозяйственное право рассматривается преимущественного как часть торгового права. Вторая позиция гласит, что в самом хозяйственном праве выделяются две составляющие: частное хозяйственное право и публичное хозяйственное право.

Заметим, что аналогичное деление может быть распространено на подавляющее большинство отраслей и институтов права. В конечном итоге вопрос 
сводится к тому, что все нормы права, независимо от того к какому институту права они принадлежат, могут быть разделены на публичные и частные.

В свою очередь, по поводу дуализма или монизма частного права скажем, что выбор какой-либо из вариаций в данном случае в большей степени зависит от правовых традиций, ментальности, сложившейся юридической практики, т.е. предопределен, главным образом, историческим типом правовой общности. Законодательные оформления, выражающиеся в создании какого-либо кодекса (к примеру, торгового), либо в отмене его действия (и включении соответствующих норм в гражданский кодекс) носят прикладной характер. Они отображают ту позицию, которая получила реализацию на официальном уровне, и которая может быть изменена волеизъявлением законодателя в любой момент. То же можно сказать и в отношении деления права на гражданское и хозяйственное.

Стоит обратить внимание на то, что представители различных научных позиций, как правило, стремятся к выявлению отраслей частного и публичного права. Сложность такого выявления, вызываемые им дискуссии, по нашему мнению, предопределены самой подстановкой вопроса.

В настоящее время практически каждое объединение норм права, практически все институты и отрасли права в той или иной мере сочетают в себе частное и публично-правовое начала. Как раз по этой причине мы полагаем более обоснованным и целесообразным вести речь не об отраслях и (или) институтах частного и публичного права, а именно о нормах частного и публичного права. По нашему мнению, такое деление и верно, и актуально, если дополнить его еще и нормами-принципами, носящими универсальный характер.

Далее выразим убежденность в том, что сущностное предназначение права - регламентировать общественные отношения и воздействовать на поведение субъектов, имеющих различные интересы, - обуславливает выделение в строении права таких элементов как частное право и публичное право. Эти элементы являются не просто условными классификационными элементами, а содержательными, стабильными и закономерными компонентами правового воздействия. И частное, и публичное право должно проистекать из общих принципов права. Дело в том, что частное и публичное право, отображая основные полярные направления правового воздействия, нуждаются в некоем объединяющем начале, ибо «... все нормы в рамках нормативной системы права связаны между собой по определенным правилам... Система представляет собой известным образом организованную иерархическую структуру, все элементы которой взаимосвязаны и взаимообусловлены» [Разуваев 2002, c. 51]. Таким объединяющим началом являются основные принципы права, стоящие, образно говоря, над частным и публичным правом.

Это означает, что структура права может быть представлена тремя компонентами, два из которых проистекают из первого: основные принципы права, частное право, публичное право.

Являясь структурными элементами права, частное и публичное право отражают:

1. основные принципы права, его «сердцевину»,

2. интересы субъектов права,

3. цель правового регулирования,

4. приемы и способы правового регулирования.

Учитывая указанную многоаспектность, деление права на частное и публичное следует осуществлять на основании нескольких критериев. Мы предлагаем следующие критерии:

1. превалирующий интерес субъектов права (личный или общественный по своей природе),

2. цель правового регулирования,

3. метод правового регулирования.

Частное и публичное право часто разграничивают именно по методу правового регулирования. Вместе с тем, он не является единственным критерием разграничения частного и публичного права. Метод правового регулирования носит формально-юридический характер, а этого недостаточно для разграничения элементов, отображающих сущность права и имеющих многоаспектный характер. Кроме того, метод правового регулирования избирается законодателем. Это означает, что в ряде случаев он включает в себя не только объективные, но и субъективные аспекты.

Согласно позиции С.В. Полениной: «как и при делении системы права на отрасли, группировка отраслей права в публичный и частный блоки происходит в соответствии с предметом и методом правового регулирования. Однако роль этих критериев в каждом из названных случаев не совпадает.... Из всего спектра образующих предмет регулирования элементов значение имеет практически лишь один - состав субъектов... Соответственно центр тяжести подразделения на публичное и частное право перемещается на метод правового регулирования. В сфере частного 
права все правоотношения возникают, изменяются и прекращаются по волеизъявлению их участников... В публичном праве государственные органы предстают носителем властных... полномочий, поскольку презюмируется, что они действуют в интересах общества и государства. Соответственно основной метод правового регулирования в этой сфере - отношения власти и подчинения, возникающие чаще всего из издаваемых компетентными государственными органами административно-правовых актов» [Поленина 1999, с. 9, 10]. Именно это и предопределяет тот факт, что большинство норм публичного права императивны, а нормы частного права чаще всего носят диспозитивный характер.

Неверно считать, что деление права на частное и публичное должно проводиться на основании метода правового регулирования и сведений о субъектах соответствующих правоотношений (физические лица или органы публичной власти). Во-первых, физические и юридические лица выступают в частных правовых отношениях хоть и преимущественными (по количеству и частоте), но не исключительными участниками. Само по себе знание о том, что участником правового отношения выступает, например, уполномоченный орган государственной власти, не поможет определить, является ли отношение частно- или же публично-правовым. Даже если к этому знанию добавить сведения о том, что отношения регулируются диспозитивным методом, проблема также не будет решена. Например, в области установления, изменения и (или) прекращения опеки и попечительства одной из сторон в настоящее время выступают органы государственной власти субъектов Российской Федерации. Для самих корреспондирующих отношений предусмотрена частично императивная, а частично - диспозитивная юридическая регуляция. Такие критерии как сведения о субъектах права и (или) о методе правового регулирования не обеспечивают надлежащей ясности и четкости решения вопроса о природе правоотношений опеки и попечительства.

Однако комплексный анализ, основанный на одновременном применении таких критериев, как принципы права, интересы участников правоотношений, цель правового регулирования и формально-юридические методы ее достижения, позволит констатировать, что в правоотношениях опеки (попечительства) доминирует именно публично-правовое начало. Это обусловлено наличием у государства социальной функции.

Еще раз обратим внимание, что разграничение частного и публичного права должно осуществляться на основании нескольких критериев. Это обусловлено многогранностью частного и публичного права, разноаспектностью их проявлений, а также условностью, относительностью и, как следствие, оспоримостью каждого из этих критериев по отдельности. Как, верно, указывал еще М.М. Агарков: «Вопрос об оценках подводит нас к самой опасной теме в общественных науках. Мы вступаем в область методологических споров, которыми так богата эта область знания. Кроме того, мы сталкиваемся с неопределенным субъективизмом этических, религиозных и других убеждений, которые служат критерием для оценки». Любой критерий сам по себе может быть истолкован и оценен очень по-разному. Верное предоставление о частном и публичном праве может быть получено только в результате их целостного и разноаспектного рассмотрения.

В свою очередь, говоря об условности деления права на публичное и частное, необходимо иметь в виду, что в одном и том же (с позиций исходных данных) правиле поведения, в зависимости от конкретных условий его нормативного отображения и реализации, может выдвигаться на первый план или частно-, или публично-правовое начало.

Изначально правообязанность родителей воспитывать своих детей обычно отражается в конституционном праве. Осуществляясь надлежащим образом, т.е. через правомерное поведение, ей корреспондирует норма частного права (например, ст. 63 Семейного Кодекса Российской Федерации). Приняв противоправный характер, соответствующее поведение родителей или иных законных представителей подпадет уже под действие публичного права (например, ст. 156 Уголовного Кодекса Российской Федерации).

Таким образом, при рассмотрении вопросов о дуализме права надо исходить из того, что функционированию частного и публичного права присущ взаимопереход, образно говоря, переплетения. Более того, в зависимости от ситуационного контекста многие правила поведения могут оформиться как в частно-, так и в публично-правовую норму.

Также следует оговорить, что несмотря на то, что в современной российской правовой доктрине интерес к проблеме дихотомии права весьма высок, вопросы строения и систематизации права в ней все же принято 
решать через деление права на отрасли. В этой связи необходимо отметить, что показатели определения частного и публичного права, хоть и схожи с критериями разграничения отраслей права, но не идентичны им ${ }^{1}$. Это обусловлено тем, что, фактически, каждая отрасль права сочетает в себе и частно-, и публично-правовые начала. «И в «чистых» частноправовых актах типа гражданского или торгового кодексов достаточно широко встречаются нормы публично-правового характера» [Суханов 1994, с. 31]. Вопрос лишь в том, каков баланс такого сочетания. «Подразделение системы права на частное и публичное право выходит за отраслевые рамки. Это более крупные, чем отрасль, структурные образования... Разумеется, это не исключает, а, напротив, предполагает проникновение частных начал в сферу действия правовых отношений, охватываемых публичным правом... Вместе с тем, публичные начала проникают в отрасли частноправового блока, в том числе устанавливают пределы и границы проявления частной инициативы и ответственности в случае их нарушения» [Поленина 1999, с. 9].

\section{Заключение}

В завершение настоящей работы еще раз подчеркнем, что частное и публичное право выступают универсальными составляющими интересующего нас явления и не связаны напрямую с каким-либо конкретным типом (видом) права. При этом о качестве как отдельных норм и их объединений, так и общего содержания частного и публичного права следует судить по их соответствию общим принципам права. Основополагающей, отражающей непосредственно само строение права, нам видится модель, состоящая из трех элементов:

1. основные принципы права,

2. частное право,

3. публичное право.

Эта модель вполне допускает дальнейшее выделение более мелких элементов, но не теряет при этом своего универсального и константного характера.

\footnotetext{
1 Вопрос о критериях определения отраслей права неоднократно рассматривался одним из авторов и не будет рассматриваться в настоящей статье, так как выходит за рамки ее предмета. О критериях выделения отраслей права см., например, Азми Д.М. (2012), Структура системы права: историко-теоретический и методологический анализ, Saarbrũcken; Азми Д.М. (2014), Система права и ее строение: методологические подходы и решения, Москва; Азми Д.М. (2010), Структурное строение системы права, «Государство и право» nо. 6 .
}

\section{Библиография}

Берман Г.Дж. (1988), Западная традиция права: эпоха формирования, Москва.

Болгова В.В. (2009), Римская правовая традиция и проблемы строения системы права в странах романо-германской правовой семьи, «Право и государство: теория и практика» no. 9 (57).

Давид Р., Жоффре-Спинози К. (2007), Основные правовые системы современности, Москва.

Князев В.К. К вопросу о частном праве: социально-юридические аспекты [online], www.lib.socio.msu.ru/library.

Мальцев Г.В. (2004), Частное и публичное право: проблемы теории, [в:] В.В. Безбах, В.К. Пучинский (ред.), Гражданское и торговое право зарубенных стран: Учебное пособие, Москва.

Мозолин В.П. (2003), Система российского права (доклад на всероссийской конферениии 14 ноября 2001 г.), «Государство и право» по. 1.

Пионтковский А.А. (1958), $к$ вопросу о взаимоотношении объективного и субъективного права, «Советское государство и право» по. 5.

Поленина С.В. (1999), Взаимодействие системы права и системы законодательства в современной России, «Государство и право» по. 9.

Разуваев Н.В. (2002), Критерии отраслевой дифференииачии права, «Правоведение» nо. 3 (242).

Ровный В.В (2000), Проблемы единства российского частного права. Автореферат дисс. ... докт. юрид. наук, Томск.

Суханов Е.А. (1994) Система частного права, «Вестник Московского университета». Серия 11. Право, no. 4.

Ушаков Д.Н., Толковыцй словарь [online], www.slovopedia. com.

Girard P.F., Mayr R. von. (1908), Geschichte und System des Romischen Rechtes, Berlin.

Merriman J.N. (1985), The Civil Law Tradition, Stanford.

\section{Список правовых актов}

Семейный кодекс Российской Федерации от 25 декабря 1995 года № 223-Ф3 (Российская газета. 27 января 1996 года, № 17, с изменениями и дополнениями).

Уголовный кодекс Российской Федерации от 13 июня 1996 года № 63-Ф3 (Российская газета. 18 июня 1996 года, № 113, 19 июня 1996 года, № 114, 20 июня 1996 года, № 115, 25 июня 1996 года, № 118, с изменениями и дополнениями). 